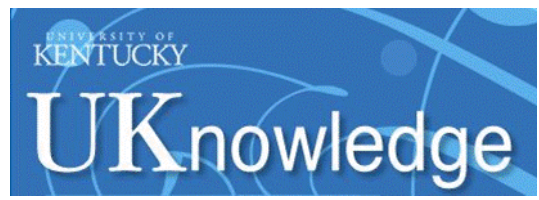

University of Kentucky

UKnowledge

Research and Education Center at Princeton

Faculty Publications

Research and Education Center at Princeton

2018

\title{
Influence of Kernel Shape and Size on the Packing Ratio and Compressibility of Hard Red Winter Wheat
}

\author{
Marvin C. Petingco \\ Kansas State University \\ Mark E. Casada \\ USDA Agricultural Research Service \\ Ronaldo G. Maghirang \\ Kansas State University \\ Sidney A. Thompson \\ University of Georgia \\ Samuel G. McNeill \\ University of Kentucky, sam.mcneill@uky.edu
}

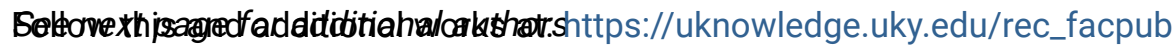

Part of the Agriculture Commons, and the Agronomy and Crop Sciences Commons

Right click to open a feedback form in a new tab to let us know how this document benefits you.

\section{Repository Citation}

Petingco, Marvin C.; Casada, Mark E.; Maghirang, Ronaldo G.; Thompson, Sidney A.; McNeill, Samuel G.; Montross, Michael D.; and Turner, Aaron P., "Influence of Kernel Shape and Size on the Packing Ratio and Compressibility of Hard Red Winter Wheat" (2018). Research and Education Center at Princeton Faculty Publications. 1.

https://uknowledge.uky.edu/rec_facpub/1

This Article is brought to you for free and open access by the Research and Education Center at Princeton at UKnowledge. It has been accepted for inclusion in Research and Education Center at Princeton Faculty Publications by an authorized administrator of UKnowledge. For more information, please contact UKnowledge@lsv.uky.edu. 


\section{Influence of Kernel Shape and Size on the Packing Ratio and Compressibility of}

Hard Red Winter Wheat

\section{Digital Object Identifier (DOI)}

https://doi.org/10.13031/trans.12648

Notes/Citation Information

Published in Transactions of the ASABE, v. 61, issue 4, p. 1437-1448.

The copyright holder has granted the permission for posting the article here.

Authors

Marvin C. Petingco, Mark E. Casada, Ronaldo G. Maghirang, Sidney A. Thompson, Samuel G. McNeill, Michael D. Montross, and Aaron P. Turner 


\title{
INFLUENCE OF KERNEL SHAPE AND SIZE ON THE PACKING RATIO AND COMPRESSIBILITY OF HARD RED WINTER WHEAT
}

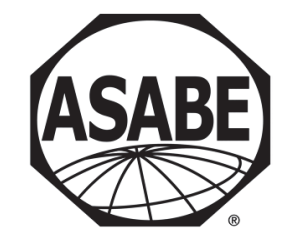

\author{
M. C. Petingco, M. E. Casada, R. G. Maghirang, S. A. Thompson, \\ S. G. McNeill, M. D. Montross, A. P. Turner
}

\begin{abstract}
Grain compaction occurs during bin storage, and its determination is important for the grain mass estimation needed for inventory and auditing. The degree of compaction is dependent on grain type, bin type, moisture content, amount of grain, initial grain bulk density, coefficients of friction, lateral-to-vertical pressure coefficient, and variation in kernel size. Previous studies have correlated several of these parameters, such as bulk density and grain packing, with moisture content. This study investigated the influence of wheat kernel shape and size distribution on packing ratio and compressibility. Two dockage-free hard red winter (HRW) wheat samples, with no shrunken or broken kernels, were sieved using U.S. Tyler sieves \#6, \#7, \#8, and \#10, and the kernels retained on the sieves were used in the experiments. The kernel dimensional parameters and bulk sample parameters were measured, and additional derived parameters were calculated for each size fraction and variety. Packing ratio and compressibility of the size fractions and of binary and ternary mixtures of the size fractions were also determined for each variety. Packing ratio increased with larger kernel size, while compressibility decreased. Sphericity and flatness shape factor had strong positive linear relationships with packing ratio and strong negative relationships with compressibility, while elongation shape factor behaved the opposite way with packing ratio and compressibility. The higher the percentage mass of the larger kernel fraction in a mixture, the higher was its packing ratio and the lower its compressibility. The two tested varieties of wheat did not significantly differ in packing ratio and compressibility. These findings can be used in developing models for more accurate estimation of grain pack factor and to determine the mass of grain inside bins and other storage structures.
\end{abstract}

Keywords. Compressibility, Packing, Shape, Size, Wheat.

$\mathrm{G}^{-}$ rain packing has been studied extensively in the past three decades (Malm and Backer, 1985; Thompson et al., 1987, 1991; Thompson and Ross, 1983) because it is important for inventory, government auditing, and loan and insurance purposes. Knowing the degree of packing of different grain crops is

Submitted for review in September 2017 as manuscript number PRS 12648; approved for publication by the Processing Systems Community of ASABE in May 2018.

Mention of company or trade names is for description only and does not imply endorsement by the USDA. The USDA is an equal opportunity provider and employer.

The authors are Marvin C. Petingco, Graduate Student, Department of Biological and Agricultural Engineering, Kansas State University, Manhattan, Kansas, and Assistant Professor, College of Engineering, Cagayan State University, Philippines; Mark E. Casada, Research Agricultural Engineer, USDA-ARS Center for Grain and Animal Health Research, Manhattan, Kansas; Ronaldo G. Maghirang, Professor, Department of Biological and Agricultural Engineering, Kansas State University, Manhattan, Kansas; Sidney A. Thompson, Professor, Department of Biological and Agricultural Engineering, University of Georgia, Athens, Georgia; Samuel G. McNeill, Associate Extension Professor, Research and Education Center, University of Kentucky, Princeton, Kentucky; Michael D. Montross, Professor, and Aaron P. Turner, Engineer Associate, Department of Biosystems and Agricultural Engineering, University of Kentucky, Lexington, Kentucky. Corresponding author: Mark E. Casada, USDA-ARS Center for Grain and Animal Health Research, 1515 College Ave., Manhattan, KS 66502; phone: 785-776-2758; e-mail: mark.casada@ars.usda.gov. necessary to accurately determine the mass of grain in a storage structure and to calculate the storage capacity of grain bins (ASABE, 2010).

Grain packing can be determined from the ratio of the initial bulk density (usually test weight) and the actual average bulk density of the grain confined in a bin. The degree of packing depends on several factors, such as type of crop, grain moisture content, initial test weight of grain, make of bin, bin dimensions, and height of grain (Bhadra et al., 2015; Boac et al., 2015). Other factors include other grain properties, such as particle-to-particle and wall surface-to-particle coefficients of friction and lateral-to-vertical pressure coefficient (Thompson et., 1987). Among these factors, the initial bulk density, moisture content, bin diameter, and grain height have the greatest effect on grain packing in bins (Thompson et al., 1987; Ross et al., 1979).

Most studies relate grain packing and bulk density with moisture content (Ross et al., 1979; Nelson, 1980; Fang and Campbell, 2000; Kalkan and Kara, 2011; Turner et al., 2016). In general, bulk density decreases with increasing moisture content. ASABE Standard D421.4 (ASABE, 2012) predicts the bulk density of different crops as a function of moisture content. Other researchers have investigated the effects of other factors on the bulk density and compressibility of grain. Bian et al. (2015) reported that higher chaff percentage resulted in a decrease in bulk density and an increase in compressibility of wheat. These findings are consistent 
with those of Bhadra et al. (2016), who reported that increasing the percentage of dockage in wheat decreased bulk density. On the other hand, McNeil et al. (2004) investigated the combined effect of broken corn and foreign material (BCFM) and moisture content on the initial bulk density and packing of corn. They found that moisture content, percentage of broken corn, and particle size significantly affected the initial bulk density. Moreover, an increase in the initial bulk density was observed with an increased concentration of fine broken corn, and a slight decrease or no change in the initial bulk density was observed with an increased concentration of coarse particles. The presence of finer particles resulted in a decrease of bulk density in wheat and an increase in bulk density of corn. This happens because the finer materials in a wheat sample have a lower density than the wheat kernels, while the fines in corn have almost the same density as the corn kernels and tend to fill the voids between kernels.

Bulk density is defined as the ratio of the grain mass to the grain volume. Given the same mass of grain, bulk density can vary depending on the volume it occupies. The more void spaces in a grain mass, the greater the volume it occupies and the lower its bulk density. Hence, grain bulk density depends on both the kernel density and the void volume between kernels. The amount of void space depends on the spatial arrangement of particles, which is dictated by kernel properties such as size, shape, and friction coefficients (Meng et al., 2012). It is also affected by the size and shape of the container or bin and the manner of filling the bin (Molenda et al., 1996). Depending on the initial arrangement of the grain kernels, the void space and bulk density will vary, as well as the compressibility and packing density. Although packing density is a widely used term, in this article we refer to it as "packing ratio" to minimize confusion because it does not have units of density.

Numerous studies have been done on the packing ratio of particles in the chemical and material industries. These studies involved the use of linear packing models for spherical and non-spherical particle mixtures (Yu and Standish, 1991, 1993a, 1993b; Yu et al., 1992, 1993, 1996; Zou and Yu, 1996), binary and ternary mixtures (Yu et al., 1992, 1993; Meng et al., 2012; Suzuki et al., 1986), multi-component spherical particles (Dodds, 1980; Suzuki et al., 1986; Stovall et al., 1986), and coarse and fine particle mixtures (Zou et al., 2011). Most of these studies involved materials such as glass beads, wood, and plastics. Non-spherical particles include cylinders, spherocylinders, ellipsoids, and disks. However, these studies considered particles of uniform shapes and sizes, and mostly dealt with fine materials. Investigations of mixtures of nonspherical particles with different shapes and sizes are limited. Moreover, packing ratio studies of real particles such as grain kernels, which come in different shapes and size distributions, are rare.

This study looked at how the shape, size, and size distribution of wheat kernels affect wheat compressibility and packing ratio. Specifically, the objectives of this study were to (1) determine the relationship between the different shape factors and packing ratio, as well as compressibility, using a single kernel size fraction and (2) determine the effect of different proportions of kernel size fractions in binary and ternary mixtures on wheat packing ratio and compressibility.

\section{Materials AND Methods}

\section{BASIS FOR VARIETY SELECTION}

Seven hard red winter (HRW) wheat varieties were analyzed for kernel size distribution. The wheat samples were cleaned by passing them through a Carter dockage tester (Seedburo Equipment Co., Des Plaines, Ill.) to remove foreign material and through a $1.63 \mathrm{~mm} \times 9.53 \mathrm{~mm}(0.064$ in. $\times 3 / 8$ in.) oblong sieve to remove shrunken and broken kernels. The kernels were sorted with a mechanical test sieve shaker (Ro-Tap, W.S. Tyler, Mentor, Ohio) using a series of $200 \mathrm{~mm}$ (8 in.) diameter sieves. The sieve sizes used were U.S. Tyler sieves \#6 (3.36 mm), \#7 $(2.83 \mathrm{~mm})$, \#8 $(2.38 \mathrm{~mm})$, and \#10 $(2.00 \mathrm{~mm})$. Table 1 shows the average percentage of kernels retained on each sieve using a $100 \mathrm{~g}$ wheat sample and shaking for $120 \mathrm{~s}$. Different varieties had different proportions of kernel size fractions. Everest, Garrison, WinterHawk, and AP503CL2 varieties had $80 \%$ to $90 \%$ of kernels retained on sieves \#7 and \#8 and only about 1\% of kernels retained on sieve \#6. On the other hand, KanMark and 1863 had sufficient kernels in each size fraction needed for this study. These two varieties had similar size distributions and were grown in the same geographic location.

\section{Wheat Kernel and Bulk Properties}

A bag of wheat $(27 \mathrm{~kg}$ ) of each variety (KanMark and 1863) was used for the study. Wheat samples were analyzed for dockage, moisture content, test weight, and amount of shrunken and broken kernels following the procedures outlined in the FGIS Grain Inspection Handbook (USDA-FGIS, 2013). The kernels were then sorted as discussed above.

Sorted kernels were exposed to room temperature and humidity for two weeks to reach equilibrium moisture content at those conditions. The conditioned samples were placed in sealed bags and inside sealed buckets before they were stored in a refrigerator for a week. ASABE Standard S352.2 (ASABE, 1988) was used to determine the moisture content of each size fraction from the two wheat varieties. Ninety kernels from each size and variety were also pulled from the samples for the determination of kernel length $(l)$, width $(w)$, and diameter $(t)$ using a caliper. These definitions of kernel axial dimensions are similar to those used by Ponce-Garcia et al. (2017).

\section{EQUIVALENT SPHERICAL DIAMETER}

Kernels vary in size and shape; thus, comparing two size groups will be facilitated by using the concept of equivalent spherical diameter $\left(d_{s}\right)$. Wheat kernels were assumed to be ellipsoidal in shape, either a prolate spheroid or an oblate spheroid, depending on the ratios of their diameters in the three dimensional axes. As such, the volume of the kernel

Table 1. Kernel size distribution and test weight of wheat varieties.

\begin{tabular}{ccccccc}
\hline & \multicolumn{6}{c}{ Percent Retained on Sieve ${ }^{[\mathrm{a}]}$} \\
\cline { 2 - 6 } Wheat Variety & $\# 6$ & $\# 7$ & $\# 8$ & $\# 10$ & Pan & Total \\
\hline Everest (Oklahoma) & 0.3 & 52.2 & 41.8 & 5.3 & 0.3 & 100.0 \\
Garrison (Oklahoma) & 0.2 & 21.6 & 60.6 & 16.0 & 1.6 & 100.0 \\
Everest (Kansas) & 1.1 & 62.4 & 31.6 & 4.6 & 0.3 & 100.0 \\
WinterHawk (Kansas) & 0.3 & 28.1 & 59.2 & 12.1 & 0.3 & 100.0 \\
AP503CL2 (Kansas) & 0.3 & 21.3 & 59.2 & 17.1 & 2.1 & 100.0 \\
KanMark (Kansas) & 14.2 & 67.3 & 15.5 & 2.8 & 0.3 & 100.0 \\
1863 (Kansas) & 9.7 & 64.0 & 22.0 & 3.9 & 0.4 & 100.0 \\
\hline
\end{tabular}

[a] Values are means of three replications. 
$\left(V_{k}\right)$ can be approximated as $V_{k}=(\pi / 6) l \cdot w \cdot t$. The equivalent spherical diameter or geometric mean diameter (Mohsenin, 1986) can then be calculated by:

$$
d_{s}=(l \cdot w \cdot t)^{1 / 3}
$$

where $d_{s}$ is the equivalent spherical diameter of the kernel $(\mathrm{mm})$, and $l, w$, and $t$ are the kernel length (mm), width (mm), and thickness $(\mathrm{mm})$, respectively.

\section{SHAPE FACTORS}

Particle shape is one of the most important features of particulate assemblies (Podczeck, 1997) and influences packing efficiency. Various methods have been used to describe particle shapes; for this study, sphericity $(\varphi)$, flatness shape factor $(\lambda)$, and elongation shape factor $(\varepsilon)$ were used. These factors were determined for each size fraction and variety.

Mohsenin (1986) estimated the sphericity of a triaxial ellipsoidal particle as the ratio of the geometric mean diameter to the diameter of the largest inscribed circle of the particle. A sphericity of 1.0 is considered a perfect sphere. Wadell (1935) used another definition of sphericity as the ratio of the surface area of a sphere of the same volume as the particle $\left(A_{s}\right)$ to the actual surface area of the particle $\left(A_{p}\right)$ :

$$
\begin{gathered}
\varphi_{1}=\frac{(l \cdot w \cdot t)^{\frac{1}{3}}}{l} \\
\varphi_{2}=\frac{A_{s}}{A_{p}}
\end{gathered}
$$

where $\varphi_{1}$ and $\varphi_{2}$ are the sphericity based on Mohsenin and Wadell, respectively.

Wadell's sphericity equation can be expressed in terms of kernel dimensions ( $l, w$, and $t$ ) by determining $A_{s}$ and $A_{p}$. For a triaxial ellipsoidal particle (with axis lengths given by $l, w$, and $t), A_{s}$ can be expressed in terms of the volume of the particle $\left(V_{p}\right)$ as:

$$
A_{s}=(\pi)^{\frac{1}{3}}\left(6 V_{p}\right)^{\frac{2}{3}}
$$

where $V_{p}=(\pi / 6) l \cdot w \cdot t$, as given by the volume of an ellipsoid.

However, $A_{p}$ is not as easy to determine as the surface area of a sphere. A good approximation of the surface area of a triaxial ellipsoid was derived by Klamkin (1971). This equation was refined by Knud Thomsen, as cited by Xu et al. (2009), such that the approximation gave the least relative error of $\pm 1.06 \%$ when $p=1.6075$. Applying Thomsen's formula for approximating the surface area of an ellipsoid to a wheat particle gives:

$A_{p}=4 \pi\left[\frac{\left(\frac{l}{2} \cdot \frac{w}{2}\right)^{1.6075}+\left(\frac{l}{2} \cdot \frac{t}{2}\right)^{1.6075}+\left(\frac{w}{2} \cdot \frac{t}{2}\right)^{1.6075}}{3}\right]^{1.6075}$
The sphericity of Wadell (1935) can be written as:

$$
\varphi_{2}=\frac{(l \cdot w \cdot t)^{\frac{2}{3}}}{\left[\frac{(l \cdot w)^{1.6075}+(l \cdot t)^{1.60745}+(w \cdot t)^{1.6075}}{3}\right]^{\frac{1}{1.6075}}}
$$

Flatness shape factor is the ratio of the kernel's width to its thickness, while elongation shape factor is the ratio of the kernel's length to its width. These shape factors are given by the following equations:

$$
\begin{aligned}
\lambda & =\frac{w}{t} \\
\varepsilon & =\frac{l}{t}
\end{aligned}
$$

where $\lambda$ and $\varepsilon$ are the flatness shape factor and elongation shape factor, respectively. A flatness shape factor of 1.0 indicates that the cross-section of the kernel is round. The higher the flatness shape factor, the flatter or more flake-like the kernel is. Similarly, an elongation shape factor of 1.0 indicates that the longitudinal section of the kernel is round. The higher the elongation ratio, the more elongated the kernel is.

\section{SAMPle Preparation}

For each variety, kernels from the four size fractions were prepared, and kernel apparent density, aerated bulk density, tapped bulk density, and test weight were determined. Approximately $800 \mathrm{~g}$ samples were used for each run in the determination of bulk density and test weight. The same amount was used for binary and ternary mixtures.

Six binary mixtures (\#6 \& \#7, \#6 \& \#8, \#6 \& \#10, \#7 \& $\# 8, \# 7 \& \# 10, \# 8 \& \# 10$ ) were also produced for each variety by mixing various mass fractions of two different size classes. In each binary mixture, the mass fraction of the smaller size class was increased from $20 \%$ to $80 \%$ in steps of $20 \%$ (at the same time, the mass fraction of the larger size class was decreased from $80 \%$ to $20 \%$ in steps of $20 \%$ ). Six ternary mixtures of kernels retained on sieves \#7, \#8, and \#10 were also produced for each variety, with proportions of $0.2-$ $0.6-0.2,0.4-0.4-0.2,0.6-0.2-0.2,0.2-0.4-0.4,0.4-0.2-0.4$, and $0.2-0.2-0.6$, respectively.

\section{Density Measurements}

The kernel apparent density was determined using a helium gas multi-pycnometer. A large cell with a volume of 148.52 $\mathrm{cm}^{3}$ was filled with a known mass of wheat. The pycnometer measures the volume occupied by the sample. By dividing the known mass of wheat by the kernel volume measured with the pycnometer, the density of the sample can be determined. In this procedure, the measured density is not the kernel apparent density but rather the kernel control density according to Chang (1988). The volume measured in this method excludes the pore spaces inside the individual kernels that are accessible to helium gas. To determine the ker-nel apparent density, the individual kernels should 
first be coated with paraffin before volume measurement with the pycnometer, and then the volume occupied by the wheat kernels can be computed. In the study by Chang (1988), the wheat kernel apparent density was 0.971 times lower than the control density. We used this relationship to calculate kernel apparent density from the pycnometer-measured density.

Carr (1965) discussed four different types of bulk densities that have a direct effect on the compressibility of a substance. Aerated or loose bulk density is determined by pouring a quantity of granular material into a container of known volume. It is called aerated because the bulk solid has not been subjected to compression or packing. In the grain industry, test weight is the common measure of aerated bulk density.

Packed bulk density is the bulk density of the material after it has been compressed. When grain is stored in bins, its bulk density is actually a packed bulk density. Packed bulk density is always higher than aerated bulk density due to a decrease in bulk volume because of displacement of the entrained air in the void spaces between particles. The Canadian Grain Commission (2014) test weight, expressed in kilograms per hectoliter, is a packed bulk density measurement.

All measurements were done in the following order to reduce variation in measurements. First, a sample of approximately $800 \mathrm{~g}$ was prepared depending on the required amount of kernel fraction in a mixture. The sample was then passed through a sample divider, and the two parts were combined. This was done five times. Aerated bulk density was then determined, followed by tapped bulk density. This sequence was repeated three times using the same $800 \mathrm{~g}$ sample.

\section{Aerated Bulk Density}

A $1000 \mathrm{~mL}$ graduated cylinder was used in the determination of aerated and tapped (or packed) bulk densities. The cylinder was cut into two parts. The lower half of the cylinder had an internal volume of $400 \mathrm{~cm}^{3}(6.35 \mathrm{~cm}$ diameter, 12.63 $\mathrm{cm}$ height). The upper half could be replaced and secured on top of the lower half by using a flexible hose connector.

To determine the aerated bulk density, only the lower half of the cylinder was used. The test used the same procedure as used for determining the test weight of wheat except that instead of the test kettle, the lower part of the cylinder (fig. 1a) was used and the filling funnel was held at a height of $5.70 \mathrm{~cm}$ above the cylinder. Dividing the mass of the grain by the cylinder volume gave us the aerated bulk density. The

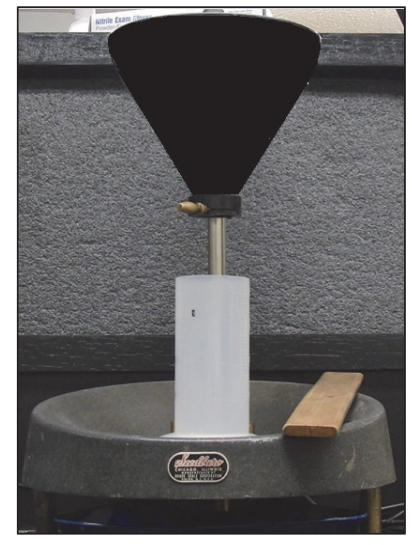

(a)

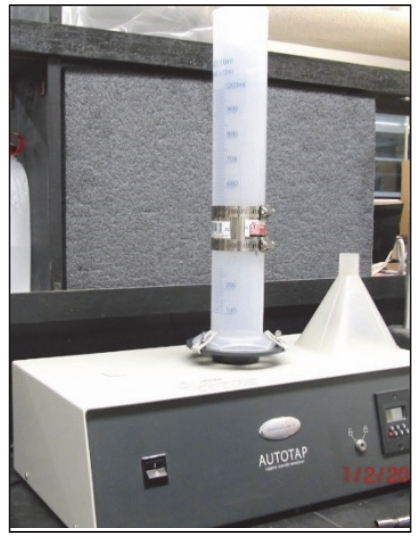

(b)
Figure 1. Bulk density measurement: (a) aerated and (b) tapped. cylinder was placed at the same location each time it was filled to limit variability in measured aerated bulk density.

\section{Tapped Bulk Density}

The packed bulk density was approximated as the tapped bulk density and was obtained by securing the upper half of the cylinder to the lower half of the cylinder that was filled with wheat during the aerated bulk density test (fig. 1b). This prevented the wheat from spilling during tapping. Tapping was done using a Quantachrome Autotap at a rate of 260 taps per minute $(4.33 \mathrm{~Hz})$ and a nominal tapping height of $3 \mathrm{~mm}$. As the grain was tapped, its level decreased, resulting in an increase in bulk density. However, because the change in height was difficult to measure, a fixed volume with varying mass was used for determining tapped bulk density. To achieve a fixed volume, an additional $150 \mathrm{~g}$ of wheat was added to the cylinder before mounting it to the Autotap and tapping 500 times. The number of taps was based on results of preliminary tests, which showed no significant change in the tapped bulk density of wheat samples after 500 taps. After tapping, the upper part of the cylinder was carefully removed, the grain was leveled using the strike-off stick, and the remaining grain was weighed. The tapped bulk density was calculated as the grain mass divided by the cylinder volume.

\section{PACKING RATIO ANd COMPRESSIBILITY}

Packing ratio is defined by Stovall et al. (1986) as the volume fraction of the system occupied by solids. When the interstitial fluid is of negligible density, the packing ratio is the bulk density divided by the true density. It can be expressed as one minus the porosity. It is also the reciprocal of the specific volume, which is defined as the apparent volume occupied by a unit volume of solid particles. A high packing ratio indicates a low percentage of interparticle voids. For this study, the tapped bulk density and the kernel apparent density were used in determining the packing ratio of wheat samples. Thus, the packing ratio of wheat particles was defined as:

$$
\Phi=\frac{\mathrm{BD}_{t}}{\mathrm{AD}}
$$

where $\Phi$ is the packing ratio (decimal), $\mathrm{BD}_{t}$ is the tapped bulk density $\left(\mathrm{kg} \mathrm{m}^{-3}\right)$, and $\mathrm{AD}$ is the kernel apparent density $\left(\mathrm{kg} \mathrm{m}^{-3}\right)$.

Compressibility indicates the difference between the aerated and packed bulk densities of the material (Carr, 1965) and was defined using the measured tapped bulk density for packed bulk density as:

$$
C=\frac{\mathrm{BD}_{t}-\mathrm{BD}_{a}}{\mathrm{BD}_{p}}
$$

where $C$ is the compressibility, and $\mathrm{BD}_{a}$ is the aerated bulk density.

Low compressibility indicates very good flowability in powder. For free-flowing granular materials such as wheat, compressibility gives a measure of packing from the initial bulk density (aerated bulk density) due to outside forces (vibration in this case) that rearrange the kernels and produce a 
higher final bulk density (tapped bulk density).

\section{Data AnAlysis}

Pairwise mean comparison using least significant difference (LSD) was used to determine if there were significant differences in parameter values among the four different size fractions and between the two varieties. Linear regression was performed, and the coefficient of determination $\left(\mathrm{R}^{2}\right)$ was used to determine the relationships between kernel size and shape factors, packing ratio and shape factors, and compressibility and shape factors. Pairwise mean comparison using LSD was also used to determine if there were significant differences among the different binary mixtures of kernel sizes and between the two varieties for the same binary mixture. A stepwise forward selection regression was performed in Minitab to determine the best-fit equations for the packing ratio and compressibility of ternary mixtures for both varieties. MATLAB was used to plot ternary diagrams of the packing ratio and compressibility of the two varieties.

\section{RESULTS AND DISCUSSION VARIETY COMPARISON}

Table 2 shows the test weight, moisture content, and percentage composition by mass of dockage, shrunken and broken kernels, and whole kernels for the two varieties. The test weight of wheat can be affected by the amount of shrunken and broken kernels, by the amount of whole kernels, and by the kernel size distribution. How the different particles are arranged can also affect the volume occupied by interparticle voids.
KanMark had a higher average test weight than 1863 . The percentages of whole kernels and of shrunken and broken kernels for both varieties were not significantly different $(p>0.05)$. Thus, the significant difference in test weight, which is a measure of bulk density, can be attributed to the difference in kernel apparent density and moisture content. The higher kernel apparent density of 1863 should have resulted in a higher test weight; however, its higher moisture content resulted in a lower test weight than KanMark because wheat kernels tend to swell with moisture and increase in volume (Thompson and Ross, 1983). The moisture content difference of $0.8 \%$ can account for a difference of $8.06 \mathrm{~kg} \mathrm{~m}^{-3}\left(0.5 \mathrm{lb} \mathrm{bu}^{-1}\right)$ in test weight using the equation in ASABE Standard D241.4 (ASABE, 2012). In addition, KanMark had a higher proportion of larger kernel size fractions (retained on sieves \#6 and \#7) that contributed to a higher test weight than 1863 (table 1). Another possible source of variation in the test weights was the difference in kernel size (table 3) and shape (table 4) for each size fraction between the two varieties.

After exposing the two wheat varieties to the same environmental conditions for two weeks, the kernel dimensions were manually determined using a Vernier caliper (table 3 ). In this article, we use the sieve number to refer to the size of the kernels that were retained on each sieve. For both varieties, the length, width, and thickness of kernels retained on each sieve decreased as the mesh size decreased. The average kernel thickness and width of the two wheat varieties for the same size fraction had very small differences, most likely because kernels were sorted on sieves based their on crosssection. However, the average length of KanMark kernels

Table 2. Test weight, moisture content, and mass composition of HRW wheat varieties 1863 and KanMark. ${ }^{\text {[a] }}$

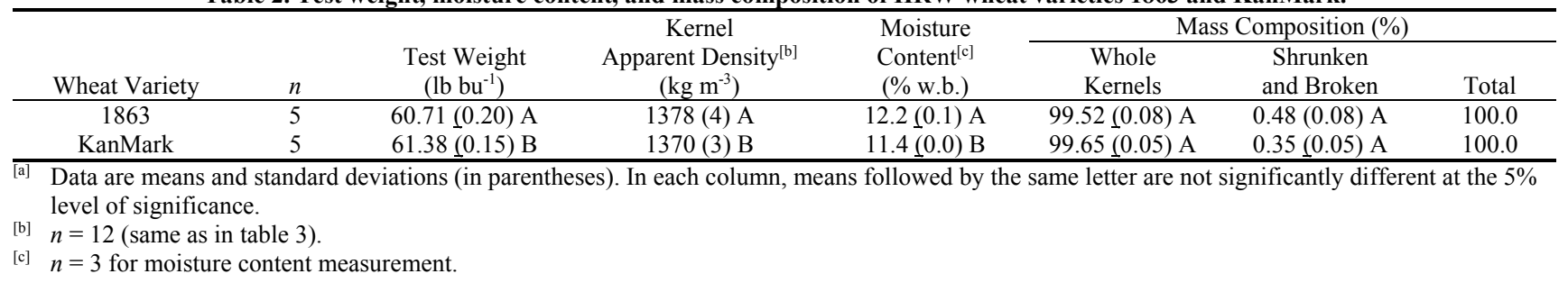

Table 3. Kernel dimensions, apparent density, and test weight for different size classes of HRW wheat varieties 1863 and KanMark. ${ }^{\text {a] }}$

\begin{tabular}{|c|c|c|c|c|c|c|c|c|c|}
\hline $\begin{array}{l}\text { Wheat } \\
\text { Variety }\end{array}$ & Size & $n$ & $\begin{array}{l}\text { Length } \\
(\mathrm{mm})\end{array}$ & $\begin{array}{l}\text { Width } \\
(\mathrm{mm})\end{array}$ & $\begin{array}{c}\text { Thickness } \\
(\mathrm{mm})\end{array}$ & $\begin{array}{c}d_{s} \\
(\mathrm{~mm})\end{array}$ & $\begin{array}{c}\text { Apparent } \\
\text { Density } \\
\left(\mathrm{kg} \mathrm{m}^{-3}\right)\end{array}$ & $\begin{array}{c}\text { Test } \\
\text { Weight }^{[b]} \\
\left(\mathrm{lb} \mathrm{bu}^{-1}\right)\end{array}$ & $\begin{array}{l}\text { Moisture } \\
\text { Content }^{[\mathrm{b}]} \\
\text { (\% w.b.) }\end{array}$ \\
\hline \multirow{4}{*}{1863} & $\# 6$ & 90 & $6.17(0.23) \mathrm{aA}$ & $3.36(0.12) \mathrm{aA}$ & $2.95(0.13) \mathrm{aA}$ & $3.94(0.12) \mathrm{aA}$ & 1379 (4) aA & $62.88(0.07) \mathrm{aB}$ & $12.36(0.03) \mathrm{cA}$ \\
\hline & $\# 7$ & 90 & $5.88(0.31) \mathrm{bA}$ & $3.01(0.16) \mathrm{bA}$ & $2.72(0.14) \mathrm{bA}$ & $3.64(0.15) \mathrm{bA}$ & 1380 (4) aA & $62.68(0.07) \mathrm{aA}$ & $12.43(0.01) \mathrm{bA}$ \\
\hline & $\# 8$ & 90 & $5.45(0.32) \mathrm{cA}$ & $2.51(0.21) \mathrm{cA}$ & $2.39(0.16) \mathrm{cA}$ & $3.19(0.16) \mathrm{cA}$ & 1375 (4) aA & $60.37(0.16) \mathrm{bA}$ & $12.58(0.02) \mathrm{aA}$ \\
\hline & $\# 10$ & 90 & $5.03(0.43) \mathrm{dA}$ & $2.03(0.24) \mathrm{dA}$ & $2.00(0.18) \mathrm{dA}$ & $2.73(0.18) \mathrm{dA}$ & 1378 (3) aA & $54.65(0.34) \mathrm{cA}$ & $12.32(0.03) \mathrm{cA}$ \\
\hline \multirow{4}{*}{ KanMark } & $\# 6$ & 90 & $5.81(0.28) \mathrm{aB}$ & $3.29(0.22) \mathrm{aB}$ & $2.92(0.17) \mathrm{aA}$ & $3.82(0.14) \mathrm{aB}$ & $1370(5) \mathrm{aA}$ & $63.40(0.21) \mathrm{aA}$ & $11.40(0.01) \mathrm{cB}$ \\
\hline & \#7 & 90 & $5.42(0.28) \mathrm{bB}$ & $2.96(0.22) \mathrm{bA}$ & $2.65(0.16) \mathrm{bB}$ & $3.49(0.16) \mathrm{bB}$ & 1370 (3) aB & $62.69(0.09) \mathrm{bA}$ & $11.39(0.00) \mathrm{cB}$ \\
\hline & $\# 8$ & 90 & $5.06(0.35) \mathrm{cB}$ & $2.46(0.21) \mathrm{cA}$ & $2.32(0.15) \mathrm{cB}$ & $3.06(0.16) \mathrm{cB}$ & 1369 (2) aA & $59.11(0.10) \mathrm{cB}$ & $11.50(0.02) \mathrm{bB}$ \\
\hline & $\# 10$ & 90 & $4.86(0.50) \mathrm{cB}$ & $1.82(0.30) \mathrm{dB}$ & $1.90(0.23) \mathrm{dB}$ & $2.55(0.24) \mathrm{dB}$ & $1370(3) \mathrm{aB}$ & $54.80(0.14) \mathrm{dA}$ & $11.75(0.03) \mathrm{aB}$ \\
\hline \multirow{4}{*}{ Combined } & \#6 & 180 & $5.99(0.31) \mathrm{a}$ & $3.32(0.18) \mathrm{a}$ & $2.93(0.15) \mathrm{a}$ & $3.88(0.14) \mathrm{a}$ & $1374(7) \mathrm{a}$ & $63.14(0.31) \mathrm{a}$ & $11.88(0.53) \mathrm{a}$ \\
\hline & \#7 & 180 & $5.65(0.38) b$ & $2.98(0.19) b$ & $2.69(0.15) b$ & $3.56(0.17) b$ & $1375(6) \mathrm{a}$ & $62.69(0.07) \mathrm{a}$ & $11.91(0.57) \mathrm{a}$ \\
\hline & $\# 8$ & 180 & $5.25(0.39) \mathrm{c}$ & $2.48(0.21) \mathrm{c}$ & $2.35(0.16) \mathrm{c}$ & $3.13(0.17) \mathrm{c}$ & 1372 (4) a & $59.74(0.70) b$ & $12.04(0.59) \mathrm{a}$ \\
\hline & $\# 10$ & 180 & $4.95(0.47) \mathrm{d}$ & $1.93(0.29) \mathrm{d}$ & $1.95(0.21) \mathrm{a}$ & $2.64(0.23) \mathrm{d}$ & $1374(5) \mathrm{a}$ & $54.73(0.25) \mathrm{c}$ & $12.03(0.32) \mathrm{a}$ \\
\hline \multicolumn{10}{|l|}{ Average } \\
\hline \multirow{2}{*}{\multicolumn{2}{|c|}{$\begin{array}{c}1863 \\
\text { KanMar }\end{array}$}} & 360 & $5.64(0.54) \mathrm{a}$ & $2.73(0.54) \mathrm{a}$ & $2.51(0.39) \mathrm{a}$ & $3.37(0.48) \mathrm{a}$ & 1378 (4) a & $60.15(3.57) \mathrm{a}$ & $12.42(0.11) \mathrm{a}$ \\
\hline & & 360 & $5.29(0.51) b$ & $2.63(0.60) b$ & $2.45(0.42) b$ & $3.23(0.51) b$ & $1370(3) b$ & $60.00(3.47) \mathrm{a}$ & $11.51(0.15) b$ \\
\hline
\end{tabular}

[a] Data are means and standard deviations (in parentheses). In each column, means followed by the same lowercase letter are not significantly different at the 5\% level between size fractions and variety; different uppercase letters indicate significant differences between varieties for the average.

[b] $n=3$ for apparent density, test weight and moisture content in each size class, and $n=24$ for the average apparent density, test weight, and moisture content for each variety 
Table 4. Kernel shape factors for different size classes of HRW wheat varieties 1863 and KanMark. ${ }^{[a]}$

\begin{tabular}{|c|c|c|c|c|c|c|c|c|}
\hline \multirow[b]{2}{*}{$\begin{array}{l}\text { Wheat } \\
\text { Variety }\end{array}$} & \multirow[b]{2}{*}{ Size } & \multirow[b]{2}{*}{$n$} & \multicolumn{2}{|c|}{ Sphericity } & \multirow[b]{2}{*}{$\begin{array}{c}\text { Flatness } \\
(\lambda)\end{array}$} & \multirow[b]{2}{*}{$\begin{array}{c}\text { Elongation } \\
(\varepsilon)\end{array}$} & \multirow[b]{2}{*}{$\begin{array}{l}\text { Packing Ratio } \\
(\Phi)^{[\mathrm{b}]}\end{array}$} & \multirow[b]{2}{*}{$\begin{array}{l}\text { Compressibility } \\
(C)^{[b]}\end{array}$} \\
\hline & & & $\begin{array}{c}\text { Mohsenin } \\
\left(\varphi_{1}\right)\end{array}$ & $\begin{array}{c}\text { Wadell } \\
\left(\varphi_{2}\right) \\
\end{array}$ & & & & \\
\hline \multirow{4}{*}{1863} & $\# 6$ & 90 & $0.64(0.02) \mathrm{aB}$ & $0.93(0.01) \mathrm{aB}$ & $1.14(0.04) \mathrm{aA}$ & $2.10(0.10) \mathrm{dA}$ & $0.632(0.001) \mathrm{aB}$ & $0.052(0.003) \mathrm{cA}$ \\
\hline & $\# 7$ & 90 & $0.62(0.02) \mathrm{bB}$ & $0.92(0.01) \mathrm{bB}$ & $1.11(0.06) \mathrm{aA}$ & $2.17(0.12) \mathrm{cA}$ & $0.631(0.001) \mathrm{aA}$ & $0.055(0.001) \mathrm{bcA}$ \\
\hline & \#8 & 90 & $0.59(0.03) \mathrm{cB}$ & $0.91(0.02) \mathrm{cB}$ & $1.05(0.10) \mathrm{bA}$ & $2.29(0.17) \mathrm{bA}$ & $0.612(0.002) \mathrm{bA}$ & $0.059(0.001) \mathrm{bA}$ \\
\hline & $\# 10$ & 90 & $0.54(0.04) \mathrm{dA}$ & $0.88(0.04) \mathrm{dA}$ & $1.02(0.12) \mathrm{bA}$ & $2.53(0.24) \mathrm{aA}$ & $0.558(0.001) \mathrm{cA}$ & $0.066(0.001) \mathrm{aA}$ \\
\hline \multirow{4}{*}{ KanMark } & \#6 & 90 & $0.66(0.03) \mathrm{aA}$ & $0.94(0.01) \mathrm{aA}$ & $1.13(0.10) \mathrm{aA}$ & $1.99(0.12) \mathrm{cB}$ & $0.638(0.001) \mathrm{aA}$ & $0.046(0.003) \mathrm{dB}$ \\
\hline & \#7 & 90 & $0.65(0.03) \mathrm{aA}$ & $0.93(0.01) \mathrm{aA}$ & $1.12(0.08) \mathrm{aA}$ & $2.05(0.14) \mathrm{cB}$ & $0.633(0.001) \mathrm{bA}$ & $0.051(0.002) \mathrm{cB}$ \\
\hline & \#8 & 90 & $0.61(0.03) \mathrm{bA}$ & $0.92(0.02) \mathrm{bA}$ & $1.06(0.09) \mathrm{bA}$ & $2.18(0.15) \mathrm{bB}$ & $0.599(0.001) \mathrm{cB}$ & $0.059(0.001) \mathrm{bA}$ \\
\hline & $\# 10$ & 90 & $0.53(0.06) \mathrm{cA}$ & $0.87(0.04) \mathrm{cB}$ & $0.96(0.14) \mathrm{cB}$ & $2.60(0.45) \mathrm{aA}$ & $0.557(0.002) \mathrm{dA}$ & $0.064(0.001) \mathrm{aA}$ \\
\hline \multirow{4}{*}{ Combined } & $\# 6$ & 180 & $0.65(0.02) \mathrm{a}$ & $0.93(0.01) \mathrm{a}$ & $1.14(0.08) \mathrm{a}$ & $2.05(0.12) \mathrm{d}$ & $0.635(0.003) \mathrm{a}$ & $0.049(0.004) \mathrm{d}$ \\
\hline & \#7 & 180 & $0.63(0.03) b$ & $0.93(0.01) b$ & $1.11(0.07) \mathrm{a}$ & $2.11(0.14) \mathrm{c}$ & $0.632(0.001) \mathrm{a}$ & $0.053(0.003) \mathrm{c}$ \\
\hline & $\# 8$ & 180 & $0.60(0.03) \mathrm{c}$ & $0.91(0.02) \mathrm{c}$ & $1.06(0.09) b$ & $2.24(0.17) b$ & $0.606(0.007) b$ & $0.059(0.001) b$ \\
\hline & $\# 10$ & 180 & $0.54(0.05) \mathrm{d}$ & $0.87(0.03) \mathrm{d}$ & $0.99(0.14) \mathrm{c}$ & $2.57(0.36) \mathrm{a}$ & $0.558(0.001) \mathrm{c}$ & $0.065(0.001) \mathrm{a}$ \\
\hline \multicolumn{9}{|l|}{ Average } \\
\hline \multirow{2}{*}{\multicolumn{2}{|c|}{$\begin{array}{c}1863 \\
\text { KanMark } \\
\end{array}$}} & 360 & $0.60(0.05) \mathrm{b}$ & $0.91(0.02) \mathrm{a}$ & $1.08(0.10) \mathrm{a}$ & $2.27(0.23) \mathrm{a}$ & $0.609(0.031) \mathrm{a}$ & $0.058(0.006) \mathrm{a}$ \\
\hline & & 360 & $0.61(0.06) \mathrm{a}$ & $0.91(0.04) \mathrm{a}$ & $1.07(0.12) \mathrm{a}$ & $2.21(0.34) \mathrm{b}$ & $0.607(0.034) \mathrm{a}$ & $0.055(0.008) \mathrm{a}$ \\
\hline
\end{tabular}

was always greater than that of 1863 for the same size fraction because of the inherent shape traits of the two wheat varieties. The equivalent spherical diameters followed the same trend (increasing with larger size fraction) because they were derived from the kernel dimensions.

Although each size fraction passed through the same sieve, the dimensions of 1863 kernels were always larger than those of KanMark. This happened because the kernels that were retained on each sieve had a size range. The sieve on which kernels were retained dictated the lower limit of the size range, while the sieve that the kernels passed through dictated the upper limit of the size range. The size distribution for 1863 included more kernels with sizes closer to the upper end of each size fraction, which caused 1863 kernels to have larger dimensions than KanMark kernels for each size fraction, even if all the kernels passed through the same sieve.

The average kernel apparent density of 1863 was higher than that of KanMark. However, the kernel apparent density was the same across all size fractions within the same variety. This indicates that the kernel apparent density varied significantly between varieties, but not across size fractions of the same variety. This agrees with the observation by Chang (1988) that different varieties can have slightly different apparent densities even if they belong to the same wheat class.

Test weight generally decreased with decreasing kernel size. In general, the test weight of 1863 was higher than that of KanMark, except for sizes \#7 and \#10, where there were no significant differences between the two varieties. The average test weight of each variety in table 3 is lower than the values shown in table 2 because the former is the average test weight of each size fraction for each variety, while the latter is the test weight of each variety with the size fraction distribution shown in table 1 and having some shrunken and broken kernels. Thus, test weight is affected by the size and size distribution of kernel fractions, including shrunken and broken kernels.

The moisture content variation across size fractions did not show a clear trend. Combining the two varieties for the analysis of moisture content showed that the effect of size on moisture content was not significant ( $p>0.05)$. The moisture content of 1863 remained higher than that of KanMark even after exposing both varieties to the same environmental conditions. Thus, the moisture contents were not equal because the two varieties had different equilibrium moisture contents for these environmental conditions.

\section{EFFect OF Size AND SHAPE Factors}

The shape factors are summarized in table 4 . For both sphericity values, the effect of size was statistically significant for both varieties; that is, it increased as size increased. In general, both sphericity values were greater for KanMark than for 1863 . However, the Wadell sphericity was higher than the Mohsenin sphericity. The reason is that the Mohsenin equation is based on the geometric mean diameter for a particle that resembles a sphere, while the Wadell equation computes the sphericity, assuming a perfect ellipsoid, as the ratio of the surface area of a sphere having the same volume as the particle to the actual surface area of the particle. Because sphericity is not easy to determine accurately due to the difficulty in measuring the surface area of a particle, both estimates of sphericity were used in this study.

The flatness increased as the kernel size increased. Generally, this indicates that the kernel cross-section became flatter or less round as the kernel size increased. However, the flatness values for kernel sizes \#6 and \#7 were not significantly different from each other. Flatness values ranged from 0.96 to 1.14 , which suggests that the wheat kernels had a relatively round cross-section. On average, the flatness values of the two wheat varieties were not significantly different.

Elongation increased as kernel size decreased, which suggests that smaller kernels were more elongated. On average, 1863 had more elongated kernels than KanMark.

For both varieties, the packing ratio increased significantly with an increase in kernel size, while compressibility decreased. There were significant differences in packing ratio and compressibility between the two varieties for the same size fraction due to the differences in kernel dimensions and shape factors for each size fraction. However, the average packing ratio and compressibility for both varieties did not vary significantly.

Figure 2 shows plots of the shape factors against the average equivalent spherical diameter $\left(d_{s}\right)$ for each size class. 
The shape factors had strong linear relationships with kernel size $\left(d_{s}\right)$. The two lines drawn for the shape factors for each variety have slightly different slopes, which suggests that the two varieties have slightly different shape factors. Minitab 17.0 Stat $>$ Regression $>$ Fit Regression Model was used to determine if there were significant differences between the coefficients of the regression equations. For each test, the shape factor was used as the response variable, $d_{s}$ was the continuous predictor, and the variety was the categorical variable. In addition, the interaction term " $d_{s} \times$ variety" was included in the model. Tests of the difference between the regression coefficients of the two regression equations, corresponding to each variety, showed that there were no significant differences for all shape factors. Thus, for the analysis of the effect of shape on packing ratio and compressibility of wheat, the two varieties were treated as one.

The linear relationships between compressibility and packing ratio with the different shape factors are shown in figure 3. All shape factors showed a linear relationship (dashed lines) with packing ratio $\left(\mathrm{R}^{2}=0.87\right.$ to 0.91$)$. Sphericity and flatness had a positive linear relationship with packing ratio, while elongation had a negative linear relationship. If the kernels in each size fraction were of perfect spherical shape and of the same size, there would be no variation in packing ratio because mono-sized spherical particle assemblies are independent of particle size. However, because the kernels in each size fraction were ellipsoidal in shape and not uniform in size, the packing ratio varied depending on the different orientations of the kernels as they filled the cylindrical container. For wheat kernels, the more spherical and flat the kernels were, the higher the packing ratio was, while a lower packing ratio occurred with kernels that were more elongated in shape.

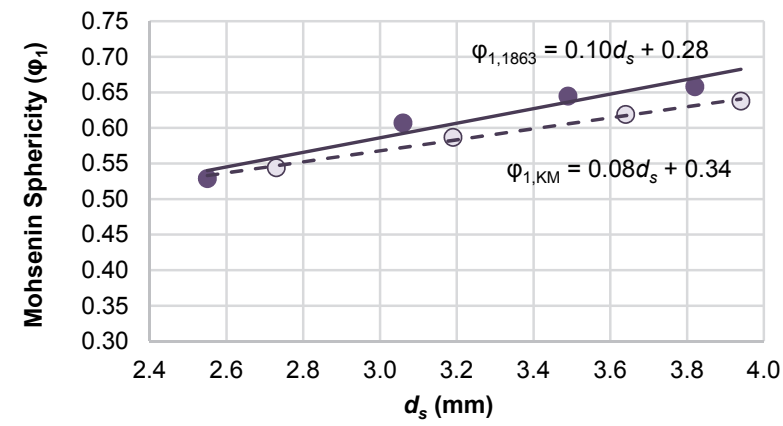

(a)

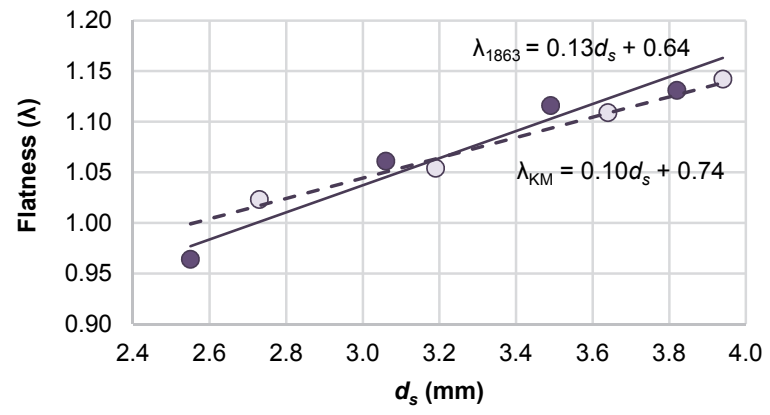

(c)
For compressibility (solid lines in fig. 3), elongation had the strongest linear relationship $\left(\mathrm{R}^{2}=0.88\right)$, followed by sphericity $\left(\mathrm{R}^{2}=0.83\right.$ and 0.85$)$ and flatness $\left(\mathrm{R}^{2}=0.79\right)$. Sphericity and flatness had negative linear relationships with compressibility. This indicates that the more spherical or flake-like the kernels were, the less compressible they were. On the other hand, elongation had a positive linear relationship with compressibility, which indicates that the more elongated the kernels were, the more compressible they were.

In figure 4, the data points can be grouped into two sets (for the two varieties) for both packing ratio and compressibility. This is because the two varieties had different bulk densities and kernel apparent densities. However, for the same size class, the kernel apparent density and compressibility were almost the same for both varieties (table 4). These results all suggest that the compressibility and packing ratio were both affected by kernel shape and size and not so much by wheat variety.

\section{EFFECT OF SIZE DISTRIBUTION}

Size, shape, and variety were found to affect compressibility and packing ratio of the wheat kernels. The effect of mixing the two size fractions was also investigated to help determine how kernel size distribution affected these properties.

\section{Binary Mixtures}

The experimental packing ratio and compressibility values of six binary mixtures of different kernel sizes are plotted in figure 4. The primary horizontal axis (bottom) for each plot corresponds to the mass fraction of the smaller kernel size in the binary mixture, while the secondary horizontal axis (top) corresponds to the mass fraction of the larger kernel size.

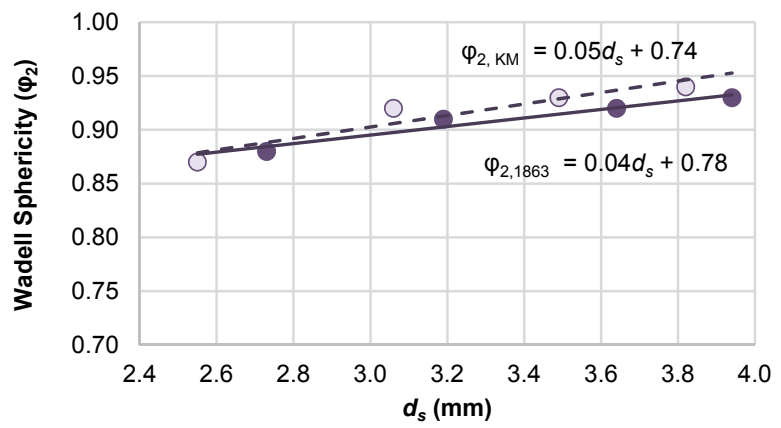

(b)

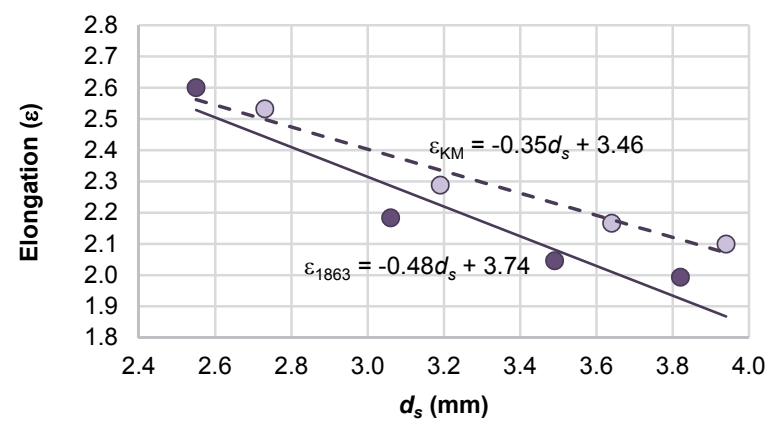

(d)

○ KanMark •1863

Figure 2. Shape factors for different size classes (equivalent spherical diameter, $d_{s}$ ) of HRW wheat varieties KanMark and 1863: (a) Mohsenin sphericity, (b) Wadell sphericity, (c) flatness, and (d) elongation. 


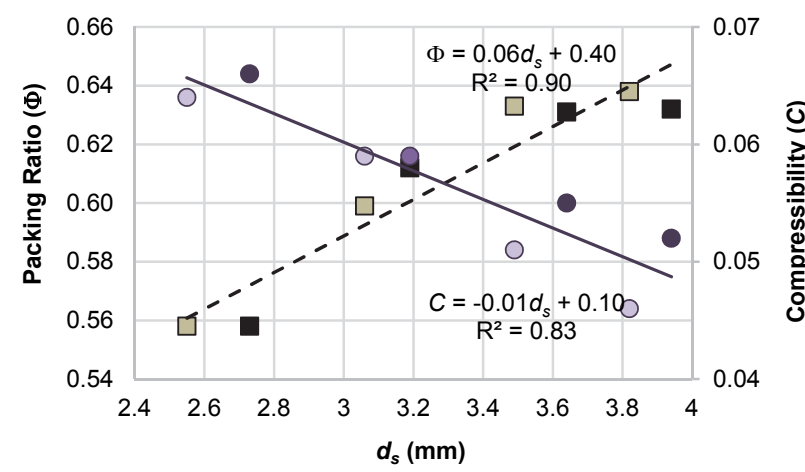

(a)

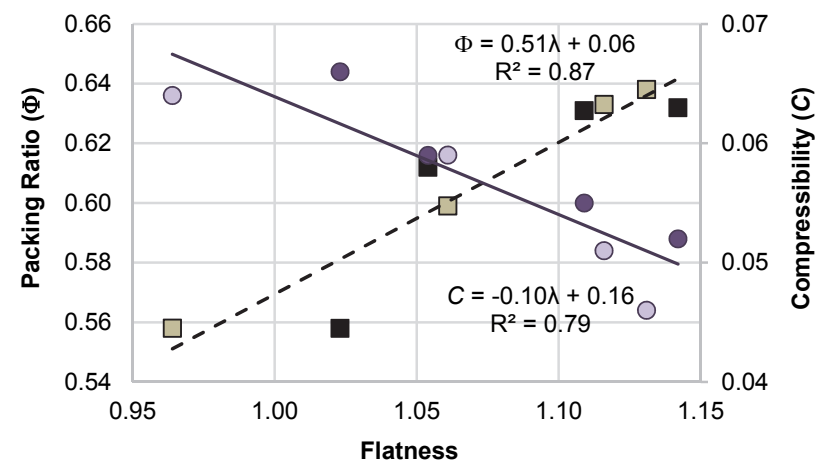

(c)

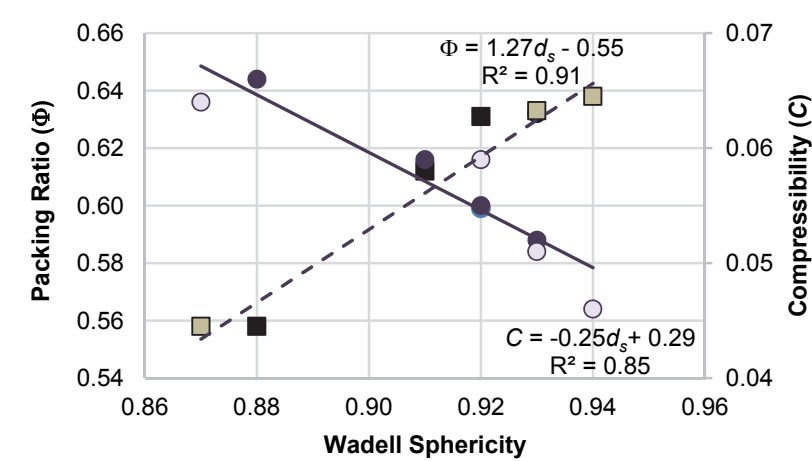

(b)

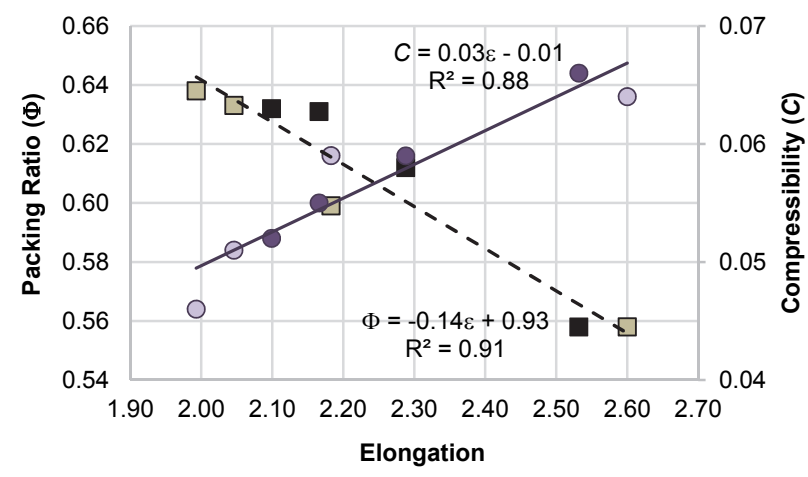

(d)

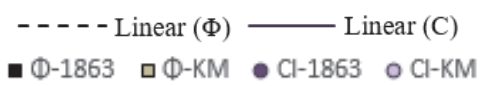

Figure 3. Packing ratio and compressibility of HRW wheat varieties KanMark (KM) and 1863 as affected by size and shape parameters: (a) equivalent spherical diameter $\left(d_{s}\right)$, (b) Wadell sphericity, (c) flatness, and (d) elongation.

The first packing ratio plot is for binary mixtures of \#6 and \#7 for both KanMark and 1863 . The packing ratio plots for both varieties are almost a straight line with zero slope. Based on the LSD pairwise mean comparison, there was no significant difference in the packing ratios among various mass fractions of \#6 and \#7 for 1863 and small differences for KanMark. This is because the packing ratios of kernel sizes \#6 and \#7 were not significantly different for 1863 but were significantly different for KanMark (table 4). This also explains why the plots of the packing ratios of binary mixtures \#6-\#8 and \#7-\#8 had the same trend and almost overlapped each other. The same is true for binary mixtures \#6$\# 10$ and \#7-\#10. In general, as the mass fraction of smaller kernels increased, the packing ratio of the mixture decreased.

The first compressibility plot is for the binary mixture of \#6 and \#7 for KanMark and 1863. Similar to the packing ratio, the compressibility of this combination was almost a zeroslope line. Even though the individual compressibility values of the \#7 and \#8 size fractions for 1863 and KanMark were significantly different (table 4), the compressibility of the combinations of $\# 7$ and $\# 8$ exhibited no significant differences for varying mass fractions of 1863 and just small differences for KanMark. Thus, the compressibility of these binary mixtures behaved differently from the compressibility of a single size fraction. This might be due to how the different kernel sizes in a mixture were arranged during measurement of aerated bulk density and how they were rearranged during tapping, which affected the measured tapped bulk density.
In general, as the mass fraction of smaller kernels increased, the compressibility of the mixture increased. Smaller kernels were more elongated and less spherical than larger kernels, which could have resulted in a more random initial arrangement of the kernels. Inducing vibration by tapping disturbed this arrangement. If the kernels were spherical and of the same size, the induced vibration would have a very little effect on their arrangement because a sphere's orientation is always the same. However, because the kernels were ellipsoidal and with different sizes and shape factors, the induced vibration resulted in a different and more packed arrangement, increasing its compressibility. Similarly, the increase in the amount of smaller and more elongated kernels resulted in higher compressibility. There were also some instances in which the compressibility of the mixture was higher than the compressibility of the smaller size fraction in the mixture, i.e., $C=0.068$ for KanMark $40 \% \# 8$ and $60 \% \# 10$ and for KanMark 20\% \#8 and 80\% \#10 as compared with $C=0.064$ for KanMark \#10, and $C=0.062$ for KanMark 20\% \#7 and 80\% $\# 10$ as compared $C=0.059$ for KanMark \#8.

Table 5 summarizes the packing ratio and compressibility of the different binary mixtures of kernel sizes for the two wheat varieties. The different combinations of kernel sizes forming a binary mixture had a significant effect on both the packing ratio and the compressibility. In general, mixtures of larger kernels had higher packing ratios but lower compressibility. It is well known that in binary mixtures of spherical particles, if the small particles are small enough to fill in the voids between the large particles, the mixture will have 


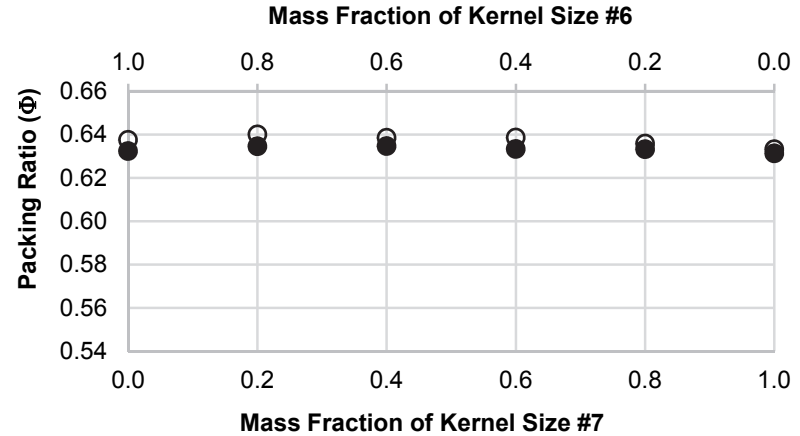

(a)

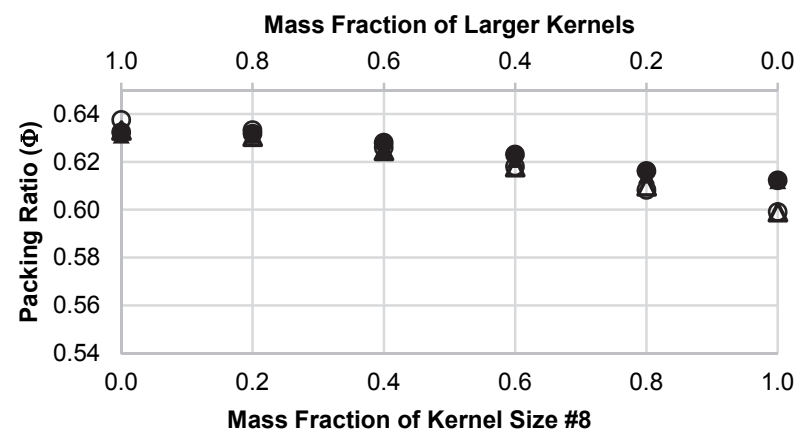

(c)

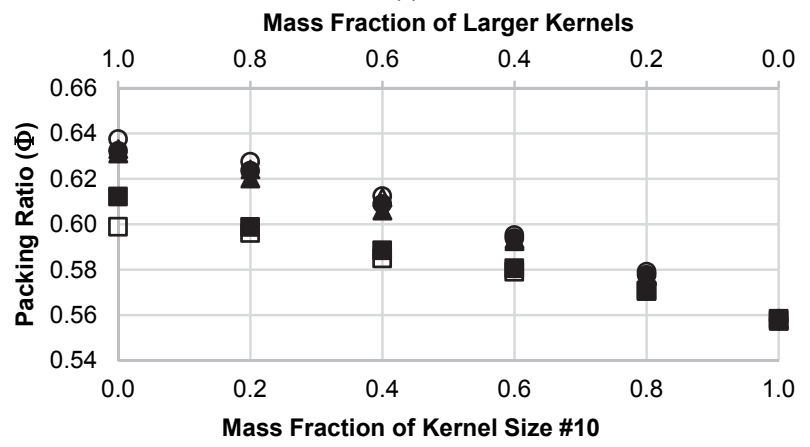

(e)

$\Delta \mathrm{KM} \# 7$

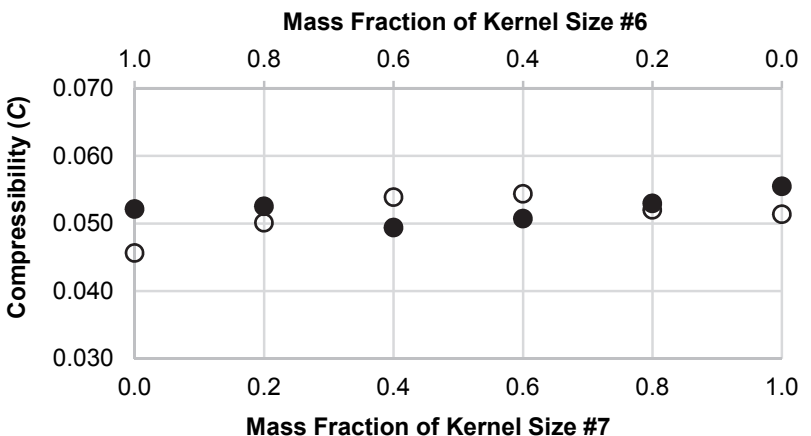

(b)

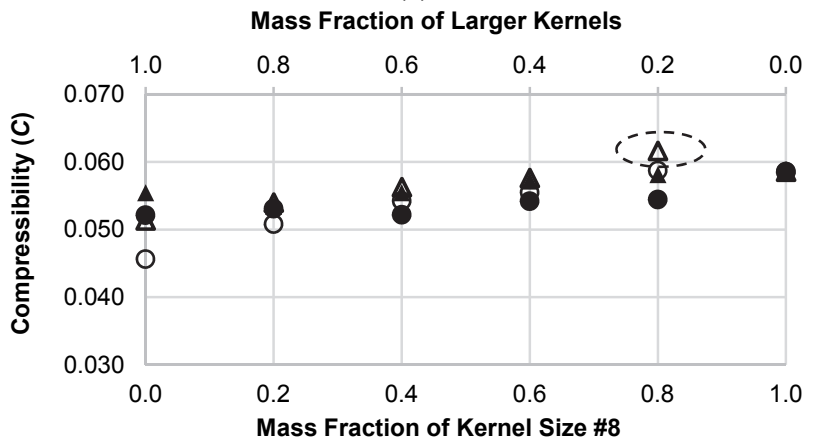

(d)

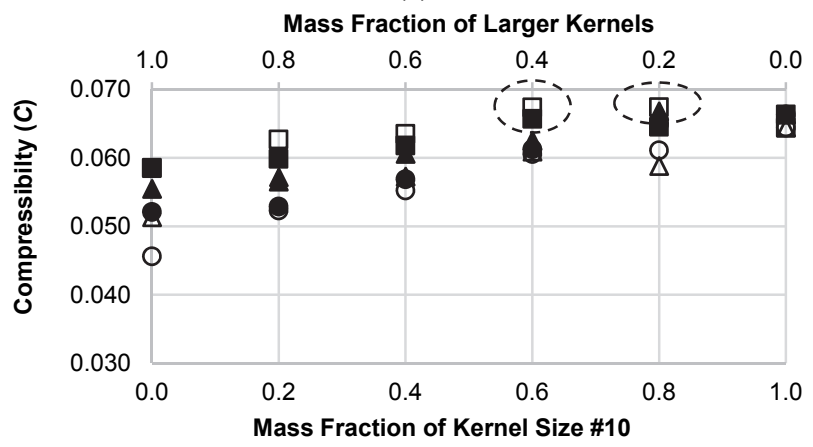

(f)

$1863 \# 6 \quad \Delta 1863 \# 7 \quad \square 1863 \# 8$

Figure 4. Packing ratio and compressibility of binary mixtures of different kernel sizes of HRW wheat varieties KanMark (KM) and 1863. Dashed circles indicate instances when the compressibility of the binary mixture was higher than that of the smaller single fraction.

a higher packing ratio. However, if the mixture consists of similar-sized particles (i.e., the size ratio in the binary mixture is close to one), the packing ratio will not change (Wong and Kwan, 2014). In addition, if the size ratio of small to large particles approaches zero, the packing ratio will increase due to either the occupying or filling effect depending on whether the larger or smaller particles are dominant. If the size ratio between the two particle sizes in a binary mixture is neither unity nor close to zero, the effect will be a decrease in the packing ratio due to either the loosening effect or the wall effect. Because the size ratios of the kernel fractions in this study were neither unity nor close to zero, the decrease in packing ratio was caused by the loosening effect of smaller particles when larger particles were dominant and by the wall effect of larger particles when smaller particles were dominant.

The variety showed no significant effect on either packing ratio or compressibility for the same combination of kernel sizes except for the combination of sizes \#6 and \#7 and the combination of sizes \#6 and \#10. Overall, variety had no significant effect on packing ratio and compressibility. This is because the two wheat varieties had kernel apparent densities for each size fractions that were close to each other and kernel size distributions that were similar. Combining these two varieties of wheat might not significantly affect compressibility and packing ratio. In bins and silos, different varieties of wheat are often mixed. In most grain facilities, when truckloads of wheat enter the facility and are transferred into bins, there is not as much mixing of different varieties, but there can be layering of different varieties in the same bin. More complete mixing occurs when the grain is moved, blended, and sold. However, if the range of kernel apparent densities of the wheat varieties is small, the compressibility and packing ratio might be more dependent on the proportions of different size fractions. For varieties that differ greatly in size fractions, the effect could be similar to the results of combining different size fractions in binary and ternary mixtures in this study. 
Table 5. Mean packing ratio and compressibility of binary mixtures of HRW wheat varieties 1863 and KanMark. ${ }^{\text {a] }}$

\begin{tabular}{|c|c|c|c|c|c|}
\hline \multirow{2}{*}{$\begin{array}{l}\text { Kernel Size } \\
\text { Combination }\end{array}$} & \multirow[b]{2}{*}{$n$} & \multicolumn{2}{|c|}{ Packing Ratio } & \multicolumn{2}{|c|}{ Compressibility } \\
\hline & & 1863 & KanMark & 1863 & KanMark \\
\hline$\# 6$ and $\# 7$ & 18 & $0.633(0.001) \mathrm{aA}$ & $0.637(0.002) \mathrm{aB}$ & $0.059(0.006) \mathrm{acA}$ & $0.051(0.004) \mathrm{aB}$ \\
\hline$\# 6$ and \#8 & 18 & $0.624(0.008) \mathrm{bA}$ & $0.620(0.014) \mathrm{bA}$ & $0.054(0.003) \mathrm{abA}$ & $0.057(0.004) \mathrm{bA}$ \\
\hline$\# 7$ and $\# 8$ & 18 & $0.622(0.008) \mathrm{bA}$ & $0.619(0.012) \mathrm{bA}$ & $0.056(0.002) \mathrm{aA}$ & $0.054(0.005) \mathrm{bA}$ \\
\hline$\# 6$ and $\# 10$ & 18 & $0.599(0.026) \mathrm{cA}$ & $0.602(0.028) \mathrm{bA}$ & $0.052(0.002) \mathrm{bA}$ & $0.057(0.007) \mathrm{bB}$ \\
\hline$\# 7$ and \#10 & 18 & $0.598(0.025) \mathrm{cA}$ & $0.600(0.027) \mathrm{bA}$ & $0.061(0.005) \mathrm{cA}$ & $0.058(0.005) \mathrm{bA}$ \\
\hline$\# 8$ and \#10 & 18 & $0.585(0.018) \mathrm{cA}$ & $0.581(0.015) \mathrm{bcA}$ & $0.063(0.003) \mathrm{acA}$ & $0.064(0.003) \mathrm{cA}$ \\
\hline All & 108 & $0.610(0.024) \mathrm{A}$ & $0.610(0.026) \mathrm{A}$ & $0.058(0.005) \mathrm{A}$ & $0.057(0.006) \mathrm{A}$ \\
\hline
\end{tabular}

\section{Ternary Mixtures}

Ternary mixtures composed of kernel sizes \#7, \#8, and \#10 were used to determine how different proportions of three kernel sizes in a mixture affect the packing ratio and compressibility. Table 6 shows the mass fractions of kernel sizes in 21 selected ternary mixtures and the results of the packing ratio and compressibility experiments. Table 7 shows the best-fit equations from stepwise linear regression with three independent variables and their interactions for both packing ratio and compressibility of the two wheat varieties.

Ternary plots of the packing ratios for both varieties showed similar trends (fig. 5). For both varieties, with $0 \%$ kernel size \#10, the packing ratio did not vary much $(0.61$ to 0.63 ). With $0 \%$ kernel size $\# 7$, the packing ratio varied from 0.57 to 0.60 , and with $0 \%$ kernel size $\# 8$, the largest variation in packing ratio was observed ( 0.57 to 0.63$)$. This shows that the effect of the proportions of different kernel sizes on the packing ratio was more pronounced when the size difference between kernels was greater, as in the case when kernel sizes $\# 7$ and \#10 were combined. In general, the increased proportion of the largest kernel size (\#7) gave the highest contribution to the increase in packing ratio (table 7). The best-fit equa- tion for the KanMark packing ratio had three significant terms, while the best-fit equation for 1863 had four terms. The coefficient of the fourth term for 1863 was very small and had little effect on the packing ratio for 1863 . The coefficients of the remaining three terms for the packing ratio equations of the two varieties were very similar to each other.

The ternary plot of compressibility for 1863 was similar to that for KanMark. The largest increase in compressibility was with an increased proportion of kernel size \#10, followed by kernel size \#8. However, the shapes of the contours were different, largely because of the difference in the fourth term (the interaction term) in the equations. For KanMark, the fourth term, which is the interaction of mass fractions of \#8 with \#10, contributed to an increase in compressibility and resulted in a peak with a constant proportion of kernel size \#7. A similar peak was shown in figure 4 (dashed circle) for the binary mixture of KanMark \#8 and \#10.

Similarly, the fourth term in the equation for 1863 , the interaction of mass fractions of \#7 with \#10, contributed to an increase in the compressibility of 1863 . The same effect can be seen with the interaction of \#8 with \#10. If there were a fifth significant term, it would be the interaction of the

Table 6. Packing ratio and compressibility of ternary mixtures of HRW wheat varieties 1863 and KanMark.

\begin{tabular}{|c|c|c|c|c|c|c|c|}
\hline \multirow[b]{2}{*}{ Sample Type } & \multicolumn{3}{|c|}{ Mass Fraction (\%) } & \multicolumn{2}{|c|}{ Packing Ratio } & \multicolumn{2}{|c|}{ Compressibility } \\
\hline & $\# 7$ & $\# 8$ & $\# 10$ & 1863 & KanMark & 1863 & KanMark \\
\hline \multirow[t]{3}{*}{ Single size fraction } & 0 & 0 & 100 & 0.559 & 0.558 & 0.066 & 0.064 \\
\hline & 0 & 100 & 0 & 0.611 & 0.599 & 0.059 & 0.059 \\
\hline & 100 & 0 & 0 & 0.632 & 0.633 & 0.055 & 0.051 \\
\hline Binary mixture & 0 & 20 & 80 & 0.571 & 0.571 & 0.065 & 0.067 \\
\hline \multirow[t]{3}{*}{$(\# 8$ and $\# 10$ with $0 \% \# 7$ ) } & 0 & 40 & 60 & 0.581 & 0.579 & 0.066 & 0.067 \\
\hline & 0 & 60 & 40 & 0.589 & 0.585 & 0.062 & 0.064 \\
\hline & 0 & 80 & 20 & 0.599 & 0.596 & 0.060 & 0.063 \\
\hline Binary mixture & 20 & 0 & 80 & 0.578 & 0.577 & 0.067 & 0.059 \\
\hline \multirow[t]{3}{*}{ (\#7 and \#10 with $0 \% \# 8$ ) } & 40 & 0 & 60 & 0.593 & 0.594 & 0.063 & 0.061 \\
\hline & 60 & 0 & 40 & 0.606 & 0.612 & 0.061 & 0.057 \\
\hline & 80 & 0 & 20 & 0.620 & 0.624 & 0.057 & 0.057 \\
\hline Binary mixture & 20 & 80 & 0 & 0.615 & 0.610 & 0.058 & 0.062 \\
\hline \multirow{3}{*}{ (\#7 and \#8 with $0 \% \# 10$ ) } & 40 & 60 & 0 & 0.621 & 0.618 & 0.057 & 0.058 \\
\hline & 60 & 40 & 0 & 0.624 & 0.625 & 0.055 & 0.056 \\
\hline & 80 & 20 & 0 & 0.631 & 0.631 & 0.053 & 0.054 \\
\hline Ternary mixture & 20 & 20 & 60 & 0.585 & 0.583 & 0.064 & 0.063 \\
\hline \multirow[t]{5}{*}{$(\# 7, \# 8$, and $\# 10)$} & 20 & 40 & 40 & 0.594 & 0.588 & 0.062 & 0.061 \\
\hline & 20 & 60 & 20 & 0.605 & 0.599 & 0.059 & 0.061 \\
\hline & 40 & 20 & 40 & 0.599 & 0.597 & 0.061 & 0.060 \\
\hline & 40 & 40 & 20 & 0.612 & 0.605 & 0.058 & 0.060 \\
\hline & 60 & 20 & 20 & 0.612 & 0.612 & 0.059 & 0.058 \\
\hline
\end{tabular}

Table 7. Best-fit equations for packing ratio and compressibility of ternary mixtures of HRW wheat varieties 1863 and KanMark.

\begin{tabular}{ccc}
\hline & Wheat Variety & Best-Fit Equation $^{[\mathrm{a}]}$ \\
\hline Packing ratio & 1863 & $\Phi=0.640\left(M_{\# 7}\right)+0.609\left(M_{\# 8}\right)+0.560\left(M_{\# 10}\right)-0.007\left(M_{\# 7}\right)^{2}$ \\
& KanMark & $\Phi=0.637\left(M_{\# 7}\right)+0.601\left(M_{\# 8}\right)+0.561\left(M_{\# 10}\right)$ \\
\hline Compressibility & 1863 & $C=0.0540\left(M_{\# 7}\right)+0.0586\left(M_{\# 8}\right)+0.0673\left(M_{\# 10}\right)+0.0051\left(M_{\# 10} \times M_{\# 7}\right)$ \\
& KanMark & $C=0.0531\left(M_{\# 7}\right)+0.0602\left(M_{\# 8}\right)+0.0642\left(M_{\# 10}\right)+0.01367\left(M_{\# 8} \times M_{\# 10}\right)$ \\
\hline
\end{tabular}

[a] $M_{\# 7}, M_{\# 10}, M_{\# 8}$ are mass fractions of kernel sizes \#7, \#8 and \#10, respectively. 


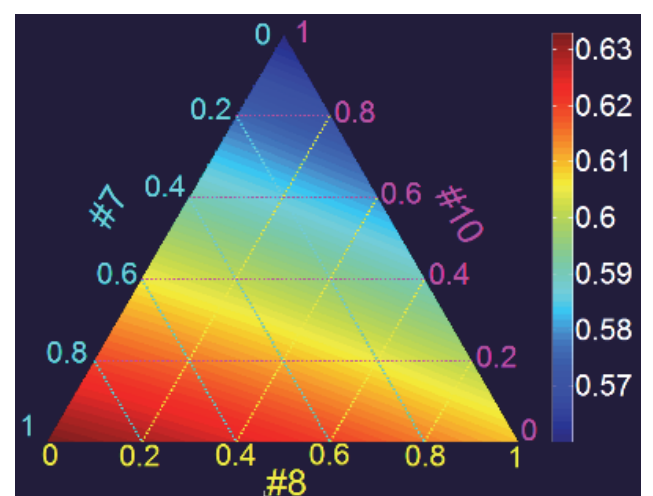

(a) 1863 packing ratio

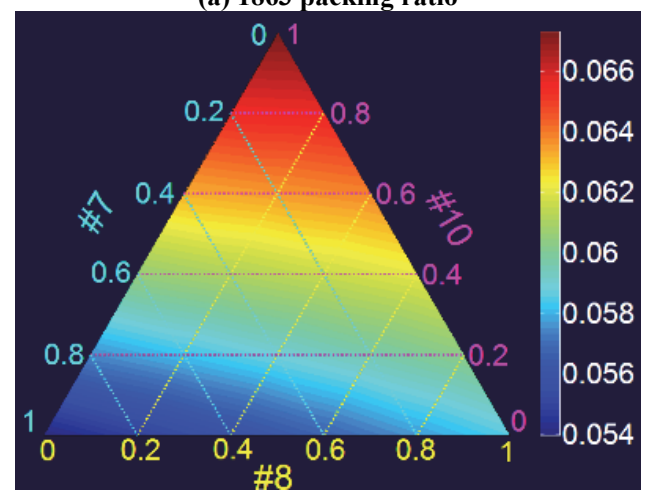

(c) 1863 compressibility

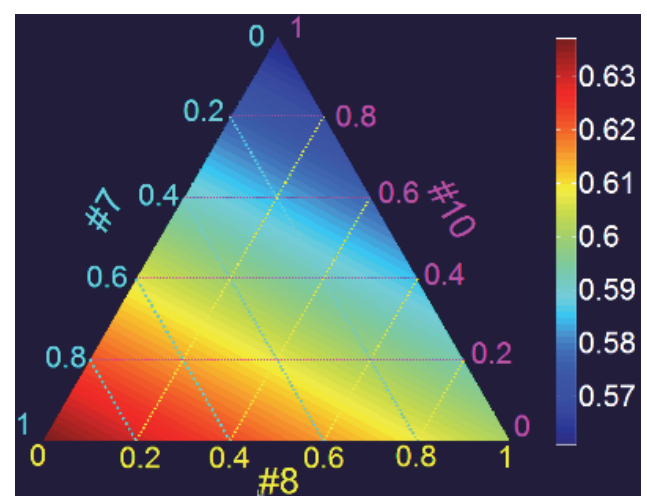

(b) KanMark packing ratio

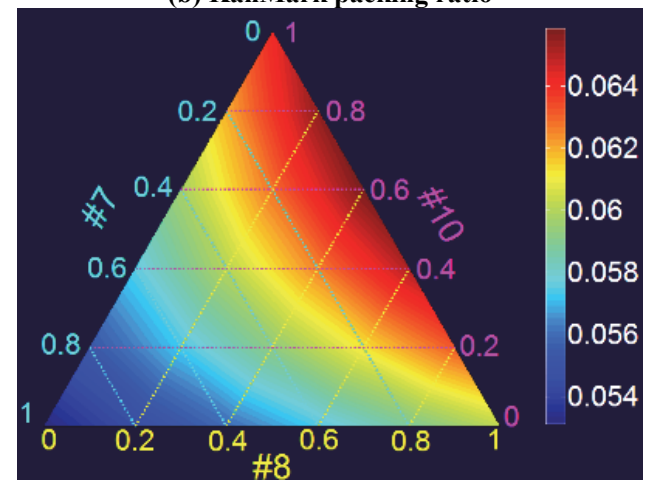

(d) KanMark compressibility

Figure 5. Ternary plots of packing ratio and compressibility of HRW wheat varieties 1863 and KanMark.

mass fractions of $\# 7$ and $\# 10$. These results were consistent with the compressibility of binary mixtures of 1863 , with the combinations \#8-\#10 and \#7-\#10 having the highest compressibility values (fig. 4).

The different compressibility behavior between the two varieties may be accounted for by the variation in the size and shape of the kernels within a given size fraction between the varieties, even though the different kernels were classified in the same size fraction when sieved. Further study is needed to understand how kernel shape and size can affect compressibility. A discrete element model simulating the aerated and tapped bulk densities of wheat kernels could be used to study how different particle sizes are arranged during the packing process. In addition, $\mathrm{x}$-ray topography could be used for determining the amount of interparticle voids in a wheat sample and for determining the packing ratio.

\section{CONCLUSION}

This research determined the effects of shape and size on the packing ratio and compressibility of two hard red winter wheat varieties (KanMark and 1863). The following conclusions were drawn:

- The packing ratio of these non-spherical particles increased with kernel size, while compressibility decreased.

- Shape factors changed with kernel size, thereby affecting compressibility and packing ratio.

- The more spherical, less elongated, and flatter the kernels, the higher the packing ratio was and the lower the compressibility was.
- Packing ratio trends were the same for single size fractions and binary mixtures of kernel fractions, while compressibility behaved differently.

- The higher the percentage of large kernels in these mixtures, the higher the packing ratio was and the lower the compressibility was.

\section{ACKNOWLEDGEMENTS}

This study was supported by The Andersons Research Grant Program, the USDA (CRIS No. 5430-43440-00800D), and by the Kansas Agricultural Experiment Station (Contribution No. 17-600-J). We would also like to thank Dr. Hulya Dogan for letting us use her laboratory and Dr. Dennis Tilley, Dr. Dan Brabec, Elizabeth Maghirang, Gari Shi, and USDA staff for their technical expertise and aid in conducting the experiments.

\section{REFERENCES}

ASABE. (1988). S352.2: Moisture measurement - Unground grain and seeds. St. Joseph, MI: ASABE.

ASABE. (2012). D421.4: Density, specific gravity, and massmoisture relationships of grain for storage. St. Joseph, MI: ASABE.

ASABE. (2010). EP413.2: Procedure for establishing volumetric capacities of cylindrical bins. St. Joseph, MI: ASABE.

Bhadra, R., Casada, M. E., Boac, J. M., Turner, A. P., Thompson, S. A., Montross, M. D., ... McNeill, S. G. (2016). Correlating bulk density (with dockage) and test weight (without dockage) for wheat samples. Appl. Eng. Agric., 32(6), 925-930. https://doi.org/10.13031/aea.32.11692

Bhadra, R., Turner, A. P., Casada, M. E., Montross, M. D., 
Thompson, S. A., Boac, J. M., ... Maghirang, R. G. (2015). Pack factor measurements for corn in grain storage bins. Trans. ASABE, 58(3), 879-890. https://doi.org/10.13031/trans.58.11033

Bian, Q., Ambrose, R. P., \& Subramanyam, B. (2015). Effect of chaff on bulk flow properties of wheat. J. Stored Prod. Res., 64(part A), 21-26. https://doi.org/10.1016/j.jspr.2015.08.004

Boac, J. M., Bhadra, R., Casada, M. E., Thompson, S. A., Turner, A. P., Montross, M. D., ... Maghirang, R. G. (2015). Stored grain pack factors for wheat: Comparison of three methods to field measurements. Trans. ASABE, 58(4), 1089-1101. https://doi.org/10.13031/trans.58.10898

Canadian Grain Commission. (2014). Test weight for Canadian grains. Winnipeg, Manitoba, Canada: Canadian Grain Commission. Retrieved from

https://www.grainscanada.gc.ca/guides-guides/weightpoids/itwm-mrps-eng.htm

Carr, R. L. (1965). Evaluating flow properties of solids. Chem. Eng., 72, 163-167.

Chang, C. S. (1988). Measuring density and porosity of grain kernels using a gas pycnometer. Cereal Chem., 65(1), 13-15.

Dodds, J. A. (1980). The porosity and contact points in multicomponent random sphere packings calculated by a simple statistical geometric model. J. Colloid Interface Sci., 77(2), 317327. https://doi.org/10.1016/0021-9797(80)90302-1

Fang, C., \& Campbell, G. M. (2000). Effect of measurement method and moisture content on wheat kernel density measurement. Food Bioprod. Proc., 78(4), 179-186. https://doi.org/10.1205/09603080051065278

Kalkan, F., \& Kara, M. (2011). Handling, frictional, and technological properties of wheat as affected by moisture content and cultivar. Powder Tech., 213(1), 116-122. https://doi.org/10.1016/j.powtec.2011.07.015

Klamkin, M. S. (1971). Elementary approximations to the area of $N$-dimensional ellipsoids. American Math. Monthly, 78(3), 280283. https://doi.org/10.2307/2317530

Malm, J. K., \& Backer, L. F. (1985). Compaction factors for six crops. Trans. ASAE, 28(5), 1634-1636. https://doi.org/10.13031/2013.32489

McNeill, S. G., Thompson, S. A., \& Montross, M. D. (2004). Effect of moisture content and broken kernels on the bulk density and packing of corn. Appl. Eng. Agric., 20(4), 475-480. https://doi.org/10.13031/2013.16477

Meng, L., Lu, P., Li, S., Zhao, J., \& Li, T. (2012). Shape and size effects on the packing density of binary spherocylinders. Powder Tech., 228, 284-294. https://doi.org/10.1016/j.powtec.2012.05.033

Mohsenin, N. N. (1986). Physical properties of plant and animal materials: Structure, physical characteristics, and mechanical properties (2nd ed.). New York, NY: Gordon and Breach.

Molenda, M., Horabik, J., \& J. Ross, I. (1996). Effect of filling method on load distribution in model grain bins. Trans. ASAE, 39(1), 219-224. https://doi.org/10.13031/2013.27501

Nelson, S. O. (1980). Moisture-dependent kernel- and bulk-density relationships for wheat and corn. Trans. ASAE, 23(1), 139-143. https://doi.org/10.13031/2013.34540

Podczeck, F. (1997). A shape factor to assess the shape of particles using image analysis. Powder Tech., 93(1), 47-53. https://doi.org/10.1016/S0032-5910(97)03257-9

Ponce-Garcia, N., Ramirez-Wong, B., Escalante-Aburto, A., Torres-Chavez, P., \& de Dios Figueroa-Cardenas, J. (2017). Mechanical properties in wheat (Triticum aestivum) kernels evaluated by compression tests: A review. In Viscoelastic and viscoplastic materials. Rijeka, Croatia: InTech. Retrieved from www.intechopen.com

Ross, I. J., Bridges, T. C., Loewer, O. J., \& Walker, J. N. (1979). Grain bin loads as affected by grain moisture content and vertical pressure. Trans. ASAE, 22(3), 592-597. https://doi.org/10.13031/2013.35068

Stovall, T., de Larrard, F., \& Buil, M. (1986). Linear packing density model of grain mixtures. Powder Tech., 48(1), 1-12. https://doi.org/10.1016/0032-5910(86)80058-4

Suzuki, M., Yagi, A., Watanabe, T., \& Oshima, T. (1986). Estimation of the void fraction in a bed randomly packed with particles of three sizes. Intl. Chem. Eng, 26(3), 491-497.

Thompson, S. A., \& Ross, I. J. (1983). Compressibility and frictional coefficients of wheat. Trans. ASAE, 26(4), 1171-1176. https://doi.org/10.13031/2013.34099

Thompson, S. A., McNeill, S. G., Ross, I. J., \& Bridges, T. C. (1987). Packing factors of whole grains in storage structures. Appl. Eng. Agric., 3(2), 215-221. https://doi.org/10.13031/2013.26677

Thompson, S. A., Schwab, C. V., \& Ross, I. J. (1991). Calibration of a model for packing whole grains. Appl. Eng. Agric., 7(4), 450-456. https://doi.org/10.13031/2013.26244

Turner, A. P., Montross, M. D., McNeill, S. G., Sama, M. P., Casada, M. E., Boac, J. M., ... Thompson, S. A. (2016). Modeling the compressibility behavior of hard red wheat varieties. Trans. ASABE, 59(3), 1029-1038. https://doi.org/10.13031/trans.59.11432

USDA-FGIS. (2013). Grain inspection handbook. Washington, DC: USDA Federal Grain Inspection Service.

Wadell, H. (1935). Volume, shape, and roundness of quartz particles. J. Geol., 43(3), 250-280. https://doi.org/10.1086/624298

Wong, V., \& Kwan, A. K. H. (2014). A three-parameter model for packing density prediction of ternary mixes of spherical particles. Powder Tech., 268, 357-367. https://doi.org/10.1016/j.powtec.2014.08.036

Xu, D., Cui, J., Bansal, R., Hao, X., Liu, J., Chen, W., \& Peterson, B. S. (2009). The ellipsoidal area ratio: An alternative anisotropy index for diffusion tensor imaging. Mag. Reson. Imaging, 27(3), 311-323. https://doi.org/10.1016/j.mri.2008.07.018

Yu, A. B., \& Standish, N. (1991). Estimation of the porosity of particle mixtures by a linear-mixture packing model. Ind. Eng. Chem. Res., 30(6), 1372-1385. https://doi.org/10.1021/ie00054a045

Yu, A. B., \& Standish, N. (1993a). Characterisation of nonspherical particles from their packing behaviour. Powder Tech., 74(3), 205-213. https://doi.org/10.1016/0032-5910(93)85029-9

Yu, A. B., \& Standish, N. (1993b). A study of the packing of particles with a mixture size distribution. Powder Tech., 76(2), 113-124. https://doi.org/10.1016/S0032-5910(05)80018-X

Yu, A. B., Standish, N., \& McLean, A. (1993). Porosity calculation of binary mixtures of nonspherical particles. J. American Ceram. Soc., 76(11), 2813-2816. https://doi.org/10.1111/j.11512916.1993.tb04021.x

Yu, A. B., Zou, R. P., \& Standish, N. (1992). Packing of ternary mixtures of nonspherical particles. J. American Ceram. Soc., 75(10), 2765-2772. https://doi.org/10.1111/j.11512916.1992.tb05502.x

Yu, A. B., Zou, R. P., \& Standish, N. (1996). Modifying the linear packing model for predicting the porosity of nonspherical particle mixtures. Ind. Eng. Chem. Res., 35(10), 3730-3741. https://doi.org/10.1021/ie950616a

Zou, R. P., \& Yu, A. B. (1996). Evaluation of the packing characteristics of mono-sized non-spherical particles. Powder Tech., 88(1), 71-79. https://doi.org/10.1016/00325910(96)03106-3

Zou, R. P., Gan, M. L., \& Yu, A. B. (2011). Prediction of the porosity of multi-component mixtures of cohesive and noncohesive particles. Chem. Eng. Sci., 66(20), 4711-4721. https://doi.org/10.1016/j.ces.2011.06.037 